\title{
USE OF MULTIVARIATE STABILITY STATISTICS TO IDENTIFY SUPERIOR TEF (Eragrostis tef [Zucc.] Trotter) GENOTYPES IN NORTHEAST ETHIOPIA
}

\author{
Fisseha WOREDE ${ }^{1 *}$, Towfik MEHADI ${ }^{2}$ \\ ${ }^{1}$ Ethiopian Institute of Agricultural Research, Fogera National Rice Research and Training Center, Bahir Dar, Ethiopia \\ ${ }^{2}$ Amhara Regional Agricultural Research Institute, Sirinka Agricultural Research Center, Woldia, Ethiopia
}

\begin{abstract}
Tef (Eragrostis Tef [Zucc.] Trotter) is a tiny-seeded cereal with huge importance in Ethiopia. Creation of variability by hybridization and the subsequent selection of Recombinant Inbred Lines (RILs) is very important towards variety development. In order to identify superior Tef genotypes, evaluation of RILs was performed on eight environments using three times replicated randomized complete block design. The result revealed that genotypes (G), environments (E) and genotype-environment interaction $(\mathrm{G} \times \mathrm{E})$ significantly $(\mathrm{P}<0.01)$ influenced grain yield of Tef. Considering the yield of genotypes on individual locations, the highest grain yield ( $4.27 \mathrm{t} / \mathrm{ha}$ ) was recorded by the genotype RIL273. The AMMI analysis showed that environment was the major contributor of the variation in grain yield; it also revealed that the best fit model was AMMI2 as the $\mathrm{G} \times \mathrm{E}$ was partitioned into two significant $(\mathrm{P}<0.01)$ Interaction Principal Component Axes (IPCAs). The two IPCAs explained 67.56\% of the G×E variance. The GGE biplot identified genotype RIL273 as the most desirable (high-yielding and stable) genotype. RIL273 is as early maturing, significantly taller and had higher yield (biomass and grain) than the checks. The genotype was released for the Northeastern part of Ethiopia and named as Lakech. It has very white seed, more preferred by consumers and have premium price at the market. Being adapted to the semi-arid areas, having higher yield and very white seed color, this variety will contribute to food security of the area.
\end{abstract}

Keywords: Eragrostis tef, Genotypes, Environments, Genotype-environment interaction, Multivariate stability

*Corresponding author: Ethiopian Institute of Agricultural Research, Fogera National Rice Research and Training Center, Bahir Dar, Ethiopia

E mail: fisseha1@yahoo.com (F. WOREDE)

$\begin{array}{lll}\text { Fisseha WOREDE (iD) https://orcid.org/0000-0001-8828-5028 } & \text { Received: February 15, 2021 }\end{array}$

Towfik MEHADI (iD) https://orcid.org/0000-0000-0000-0000

Accepted: August 31, 2021

Published: October 01, 2021

Cite as: Worede F, Mehadi T. 2021. Use of multivariate stability statistics to identify superior Tef (Eragrostis tef [Zucc.] Trotter) genotypes in Northeast Ethiopia. BSJ Agri, 4(4): 124-129.

\section{Introduction}

Tef (Eragrostis tef [Zucc.] Trotter), a tiny-seeded cereal with huge importance, has originated and diversified in Ethiopia (Vavilov, 1951). Although the crop is not as such known in the outside world, relatively large cultivable land is allotted for its production in Ethiopia. In 2018 main cropping season, 6.7 million growers cultivated 3 million ha of land and produced 5.4 million tons of Tef with a yield of $1.76 \mathrm{t} / \mathrm{ha}$ (CSA, 2019). Tef is not that much attacked by diseases and insect pests than the rest of cereal crops grown in Ethiopia (Ebba, 1969), does not need chemicals for controlling storage pest, and can easily be stored under any local storage conditions (Ketema, 1993). Because of its suitability to be grown on moisture deficit and waterlogged areas where other crops cannot successfully grow, Tef has a complementary role in Ethiopian agriculture (Ketema, 1993).

Tef has high mineral content than wheat, barley, or sorghum (Mengesha et al., 1965). The fact that it is gluten-free makes the crop preferable for celiac disease patients (Spaenij-Dekking et al., 2005). Farmers in the Northeastern part of Ethiopia grow very early-maturing local varieties during short rainy season (Belg; from
February to April) and late-maturing varieties during long rainy season (Meher; July to October), and cultivation of Tef under irrigation is not uncommon production system in the area. Tef can be intercropped with a number of oil crops (Bayu et al., 2007; Molla and Muhie, 2011), cereals (Worku, 2004; Molla and Muhie, 2011) and pulses like faba bean (Agegnehu et al., 2006). Although, Tef has the capacity to yield $4.6 \mathrm{t} / \mathrm{ha}$ when lodging is mechanically controlled by supporting the plants by mesh or nets (Teklu and Tefera, 2005), the yield attained so far in the Northeast Ethiopia is way below its yield potential. It is, therefore, necessary to continually identify high-yielding Tef varieties than the existing ones.

The small size of Tef floret, its autogamous nature (Ketema, 1997) and an hour window of flower opening time at down, 6:45 and 7:45 a.m. (Berehe, 1976), made Tef hybridization cumbersome. Moreover, the fact that the crop is endemic to Ethiopia, made the variety development process to depend on local breeders, local germplasm and naturally existing variability. Regardless of the difficulties, some works, both on intra- and interspecific hybridization, have been successful. With this 


\section{Black Sea Journal of Agriculture}

regard, an effective crossing was done between varieties Dukem (DZ-01-974) and Magna (DZ-01-196) by Debre Zeit Agricultural Research Center to combine the very white color of Magna and the high yield of Dukem into one elite variety. Consequently, intraspecific Recombinant Inbred Lines (RILs) have been developed and multi-stage multi-location evaluation of the lines have been conducted. The objective of the research was to evaluate and identify high-yielding Tef genotypes which are preferred by farmers and adapted to the semiarid areas of Northeast Ethiopia by employing multivariate stability statistics.

\section{Materials and Methods}

The experiment was conducted in Northeastern part of Ethiopia at four sites of Sirinka Agricultural Research Center: Sirinka, Kobo, Jari and Chefa in 2006 and 2007. The general descriptions of the locations are depicted in Table 1.

Table 1. The geographic, edaphic and climatic descriptions of the study areas

\begin{tabular}{|c|c|c|c|c|c|c|c|}
\hline \multirow{2}{*}{ Location } & \multirow{2}{*}{$\begin{array}{l}\text { Altitude } \\
\text { (m) }\end{array}$} & \multirow{2}{*}{ Soil type } & \multirow{2}{*}{$\begin{array}{c}\text { Rainfall } \\
(\mathrm{mm})\end{array}$} & \multicolumn{2}{|c|}{ Temperature } & \multicolumn{2}{|c|}{ Global position } \\
\hline & & & & $\operatorname{Min}\left({ }^{\circ} \mathrm{C}\right)$ & $\operatorname{Max}\left({ }^{\circ} \mathrm{C}\right)$ & Latitude & Longitude \\
\hline Kobo & 1450 & Eutric fluvisol & 637 & 15.8 & 29.1 & $12^{\circ} 8^{\prime} 21^{\prime \prime}$ & $39^{0} 18^{\prime} 21^{\prime \prime}$ \\
\hline Sirinka & 1850 & Eutric vertisol & 945 & 13.6 & 27.3 & $11^{\circ} 45^{\prime} 00^{\prime \prime}$ & $39 \circ 36^{\prime} 36^{\prime \prime}$ \\
\hline Jari & 1680 & Vertisol & NA & NA & NA & $11^{0} 21^{\prime}$ & $39^{0} 38^{\prime}$ \\
\hline Chefa & 1600 & Vertisol & 850 & 11.6 & 30.4 & $10^{0} 57^{\prime}$ & $39047^{\prime}$ \\
\hline
\end{tabular}

$\mathrm{NA}=$ not available

Fourteen RILs of Tef developed from a cross of Dukem (DZ-01-974) and Magna (DZ-01-196) were evaluated together with a farmers' variety and an improved variety Genete (DZ-01-146). A randomized complete block design (RCBD) with three replications was employed. Seeds of each genotype were broadcasted on $4 \mathrm{~m}^{2}$ plot of land at the rate of $30 \mathrm{~kg} / \mathrm{ha}$ (12 g per plot). Distances between plots and between blocks were $1 \mathrm{~m}$ and $1.5 \mathrm{~m}$, respectively. Fertilizer was applied at the rate of $41 \mathrm{~N}$ and $46 \mathrm{P}_{2} \mathrm{O}_{5} \mathrm{~kg} / \mathrm{ha}$ (50 kg/ha Urea and $100 \mathrm{~kg} / \mathrm{ha} \mathrm{DAP}$ ). Weeding was done as needed uniformly on all plots. Phonological, agronomic and yield-related data were collected both on plot and plant basis, depending on the nature of the trait. Days to maturity, biomass yield $(\mathrm{t} / \mathrm{ha})$ and grain yield $(\mathrm{t} / \mathrm{ha}$ ) were collected on plot basis. In the case of plant height $(\mathrm{cm})$ and panicle length $(\mathrm{cm})$, five randomly selected plants were measured and means were computed for each plot.

The Additive Main-effect and Multiplicative Interaction (AMMI) analysis was done according to Zobel et al. (1988) and Genotype plus Genotype-Environment interaction (GGE) analysis was performed as per Yan et al. (2000). Analysis of variance for both individual location and combined data for all traits, AMMI and GGE analyses were worked out by using GenStat 16 software.

\section{Results and Discussion}

\subsection{Genotype Performance}

The result of the RILs evaluation on eight environments (4 locations and 2 years) showed a range of mean values for the studied traits (Table 2). Days to maturity ranged from 87.4 for RIL374 to 92.4 for RIL30 and RIL52 with a mean of 89.65. Plant height varied from $87.41 \mathrm{~cm}$ for RIL374 to $101.8 \mathrm{~cm}$ for RIL273 with a mean value of $94.76 \mathrm{~cm}$. Similarly, panicle length ranged from $37.5 \mathrm{~cm}$ for DZ-01-146 to $42.7 \mathrm{~cm}$ for RIL40 having a mean of $40.24 \mathrm{~cm}$. The genotype RIL273 was the highest both in biomass- (10.89 t/ha) and grain-yield $\left(2.24 \mathrm{t} \mathrm{h}^{-1}\right)$. The highest grain yield reported in this study was lower than the one reported by Jifar et al. (2019) whereas it was higher than the grain yield reported by Worede (2020) and Balcha (2020); nonetheless, it was comparable with that of Worede et al. (2020). Genotype RIL374 and the local check were the lowest in biomass- (9.29 t/ha) and grain-yield (1.86 t/ha), respectively. The result is in harmony with the findings of Worede et al. (2020).

Considering the yield of genotypes on individual locations, the highest grain yield (4.27 t/ha) was recorded by the genotype RIL273 at SR07 (Table 3). In harmony with the present finding, highest yield of 3.349 t/ha was documented on same environment (Worede, 2020). The environment SR07 was the highest yielding (3.09 t/ha) whereas SR06 was the lowest yielding (1.45 $\mathrm{t} / \mathrm{ha}$ ) environment. In congruence with the present findings, Jifar et al. (2019) reported environmental mean grain yield of $4.29 \mathrm{t} / \mathrm{ha}$ and $1.7 \mathrm{t} / \mathrm{ha}$; Worede et al. (2020) demonstrated mean yields of 4.14 and $1.29 \mathrm{t} / \mathrm{ha}$ at the highest and lowest yielding environments, respectively. At environment SR06, the highest grain yield of $1.75 \mathrm{t} / \mathrm{ha}$ was recorded by genotype RIL205. Hence, RIL273 and RIL205 were the high yielding genotypes in the highestand lowest-yielding environments, respectively (Table 3).

The genotype RIL273 was the winner at environments KB06 and SR07. The genotype RIL205 won at SR06 and KB07. Likewise, RIL154 won at CH07; while RIL73 was first at CH06 (Table 3). This differential response of genotypes across environments shows the presence of appreciable genotype-environment interaction.

3.2. Additive Main-effect and Multiplicative Interaction analysis

The AMMI analysis of variance showed that genotypes (G), environments (E) and genotype-environment interaction $(\mathrm{G} \times \mathrm{E})$ significantly $(\mathrm{p}<0.01)$ influenced grain yield of Tef (Table 2). The result is in agreement with earlier findings reported in Tef (Jifar et al., 2019; Worede 


\section{Black Sea Journal of Agriculture}

2020; Balcha, 2020; Worede et al., 2020). The G, E and $\mathrm{G} \times \mathrm{E}$ effects explained $2.27 \%, 85.54 \%$ and $12.19 \%$ of the treatment variance. The result agrees with the findings of Worede et al. (2020) and Balcha (2020) who reported E explained $82.67 \%$ and $87.30 \%$ of the treatment variance, respectively. Environment explained the lion's share of the total treatment variance suggesting that the environments were so varied to cause most of the variation in Tef grain yield. The extent of the $\mathrm{G} \times \mathrm{E}$ variance was about five times larger than that of genotypes, indicating the presence of considerable differences in the response of Tef genotypes across environments. In line with the present finding, Jifar et al. (2019) reported environmental variance about four times higher than that of $G$ and $G \times E$.

Table 2. Mean grain yield and other agronomic traits of Tef genotypes grown at Sirinka, Kobo, Jari and Chefa in 2006 and 2007.

\begin{tabular}{lccccc}
\hline Identification & Days to maturity & $\begin{array}{c}\text { Plant height } \\
(\mathrm{cm})\end{array}$ & $\begin{array}{c}\text { Panicle length } \\
(\mathrm{cm})\end{array}$ & $\begin{array}{c}\text { Biomass yield } \\
(\mathrm{t} / \mathrm{ha})\end{array}$ & $\begin{array}{c}\text { Grain yield } \\
(\mathrm{t} / \mathrm{ha})\end{array}$ \\
\hline RIL129 & 88.8 & 94.4 & 40.0 & 9.88 & 1.91 \\
RIL40 & 89.5 & 98.2 & 42.7 & 10.51 & 1.92 \\
RIL273 & 90.2 & 101.8 & 40.1 & 10.89 & 2.24 \\
RIL37 & 87.6 & 91.1 & 38.6 & 9.58 & 1.91 \\
Local check & 90.5 & 96.5 & 39.1 & 9.55 & 1.86 \\
RIL374 & 86.9 & 87.4 & 38.7 & 9.29 & 2.07 \\
RIL351 & 88.3 & 94.5 & 38.9 & 9.68 & 1.97 \\
RIL154 & 90.7 & 95.3 & 41.1 & 10.19 & 2.03 \\
RIL52 & 92.4 & 92.5 & 38.0 & 10.02 & 1.97 \\
RIL195 & 89.2 & 96.1 & 41.1 & 10.63 & 1.88 \\
DZ-01-146 & 92.3 & 91.0 & 37.5 & 9.74 & 1.95 \\
RIL60 & 89.1 & 96.6 & 41.2 & 9.79 & 1.98 \\
RIL73 & 88.5 & 98.0 & 41.9 & 10.65 & 1.96 \\
RIL30 & 92.4 & 96.7 & 41.4 & 10.21 & 1.87 \\
RIL32 & 87.3 & 94.9 & 41.8 & 10.05 & 1.98 \\
RIL205 & 90.7 & 95.4 & 41.6 & 9.71 & 2.02 \\
\hline Mean & 89.65 & 94.76 & 40.24 & 10.02 & 1.97 \\
CV (\%) & 2.58 & 7.72 & 9.98 & 12.48 & 15.88 \\
LSD (5\%) & 1.32 & 4.16 & 2.28 & 0.712 & 0.178 \\
\hline
\end{tabular}

Table 3. Mean grain yield (t/ha) of 16 Tef genotypes grown on eight environments.

\begin{tabular}{|c|c|c|c|c|c|c|c|c|}
\hline \multirow[t]{2}{*}{ Identification } & \multicolumn{8}{|c|}{ Environments } \\
\hline & SR06 & KB06 & CH06 & JR06 & SR07 & KB07 & CH07 & JR07 \\
\hline RIL129 & 1.49 & 1.86 & 1.85 & 1.57 & 2.85 & 1.89 & 2.33 & 1.40 \\
\hline RIL40 & 1.50 & 1.51 & 2.00 & 1.24 & 3.00 & 2.24 & 2.51 & 1.37 \\
\hline RIL273 & 1.73 & 1.89 & 2.13 & 1.67 & 4.27 & 2.25 & 2.35 & 1.64 \\
\hline RIL37 & 1.40 & 1.23 & 2.21 & 1.43 & 3.32 & 1.86 & 2.38 & 1.46 \\
\hline Local check & 1.33 & 1.51 & 1.90 & 1.55 & 2.66 & 1.92 & 2.46 & 1.56 \\
\hline RIL374 & 1.44 & 1.50 & 2.12 & 1.74 & 3.31 & 2.27 & 2.71 & 1.49 \\
\hline RIL351 & 1.42 & 1.64 & 2.26 & 1.87 & 2.61 & 2.24 & 2.36 & 1.38 \\
\hline RIL154 & 1.31 & 1.38 & 2.13 & 1.57 & 3.07 & 2.29 & 2.93 & 1.59 \\
\hline RIL52 & 1.42 & 1.54 & 1.98 & 1.83 & 3.10 & 2.01 & 2.09 & 1.77 \\
\hline RIL195 & 1.29 & 1.29 & 1.64 & 1.71 & 3.12 & 2.18 & 2.45 & 1.37 \\
\hline DZ-01-146 & 1.42 & 1.30 & 2.06 & 1.44 & 3.43 & 1.56 & 2.73 & 1.68 \\
\hline RIL60 & 1.42 & 1.71 & 2.32 & 1.54 & 3.08 & 1.96 & 2.51 & 1.30 \\
\hline RIL73 & 1.32 & 1.30 & 2.17 & 1.46 & 3.33 & 1.95 & 2.46 & 1.69 \\
\hline RIL30 & 1.48 & 1.27 & 1.90 & 1.56 & 2.51 & 2.29 & 2.49 & 1.48 \\
\hline RIL32 & 1.52 & 1.09 & 1.73 & 1.57 & 3.22 & 2.29 & 2.89 & 1.52 \\
\hline RIL205 & 1.75 & 1.71 & 2.05 & 1.46 & 2.54 & 2.43 & 2.82 & 1.42 \\
\hline Mean & 1.45 & 1.48 & 2.03 & 1.58 & 3.09 & 2.10 & 2.53 & 1.51 \\
\hline CV (\%) & 14.37 & 24.36 & 20.96 & 14.83 & 13.24 & 14.87 & 11.52 & 10.28 \\
\hline LSD (5\%) & 0.151 & 0.265 & 0.307 & 0.169 & 0.295 & NS & NS & 0.112 \\
\hline
\end{tabular}

CH06 $=$ Chefa 2006, CH07 $=$ Chefa 2007, JR06= Jari 2006, JR07= Jari 2007, KB06= Kobo 2006, KB07= Kobo 2007, SR06= Sirinka 2006, SR07= Sirinka 2007 


\title{
Black Sea Journal of Agriculture
}

\author{
doi: $10.47115 /$ bsagriculture.876794
}

The AMMI analysis also showed that the best fit model was AMMI2 in this experiment, as the $\mathrm{G} \times \mathrm{E}$ was partitioned into two significant $(\mathrm{p}<0.01)$ Interaction Principal Component Axes (IPCAs). The two IPCAs explained 46.53 and $21.03 \%$, totally $67.56 \%$, of the $\mathrm{G} \times \mathrm{E}$ sum of squares (Table 4). In agreement with the present finding, 72.5\% (Jifar et al., 2019) and 66.06\% (Worede, 2020) of the total $\mathrm{G} \times \mathrm{E}$ were reported to be explained by the first two IPCAs. In AMMI1 biplot, distances along the abscissa shows differences in main effects, both genotype and environment. Accordingly, the AMMI1 biplot showed that most of the in breed lines, except RIL273, had more or less similar genotypic main effect, as they are vertically arranged in the two-dimensional plane (Figure
1). The result is in harmony with the findings of Worede (2020). Gauch and Zobel (1996) stated that genotype IPCA scores show the stability of cultivars over environments; genotypes with near-zero IPCA scores are considered to be more stable over all the environments considered. With this regard, the genotypes considered in the present study were very much different in their interaction to the environment. Genotypes RIL273, RIL205, DZ-01-146, RIL30 and RIL351 had relatively higher IPCA1 score, meaning comparatively higher $\mathrm{G} \times \mathrm{E}$ interaction, hence highly influenced by the environments. Nonetheless, genotypes RIL60, RIL32, RIL195 and RIL374 were least influenced by the environment as they had minimum IPCA1 score or $\mathrm{G} \times \mathrm{E}$ (Figure 1 ).

Table 4. AMMI analysis of variance for grain yield of 16 Tef genotypes

\begin{tabular}{lccccc}
\hline Sources of variation & df & SS & MS & $\begin{array}{c}\text { Variance explained } \\
(\%)\end{array}$ & $\begin{array}{c}\text { G } \times \text { E explained } \\
(\%)\end{array}$ \\
\hline Treatments & 127 & 46.006 & 0.362 & & \\
Genotypes (G) & 15 & 1.046 & 0.0697 & 2.27 & \\
Environments (E) & 7 & 39.353 & $5.6218^{* *}$ & 85.54 & 46.53 \\
Interactions (G×E) & 105 & 5.607 & $0.0534^{* *}$ & 12.19 & 21.03 \\
IPCA 1 & 21 & 2.609 & $0.1242^{* *}$ & & \\
IPCA 2 & 19 & 1.179 & $0.0621^{* *}$ & & \\
Residuals & 65 & 1.819 & 0.0280 & & \\
\hline
\end{tabular}

**= significant at 0.01 probability level. $\mathrm{df}=$ degrees of freedom, $\mathrm{SS}=$ sum of squares, $\mathrm{MS}=$ mean squares

The environmental main effect, nevertheless, didn't show any pattern, as the environments are scattered in the two-dimensional plane (Figure 1). Environments SR06, KB06, JR06 and JR07 had below average grain yield; whereas SR07, CH07, KB07 and CH06 had above average grain yield. Environment SR07 was the highest-yielding environment, and it also exerted the highest interaction effect. Likewise, KB06, SR06 and JR06 had more or less similar interaction pattern; while $\mathrm{CH06}$ and JR07 exerted minimum interaction effects (Figure 1).

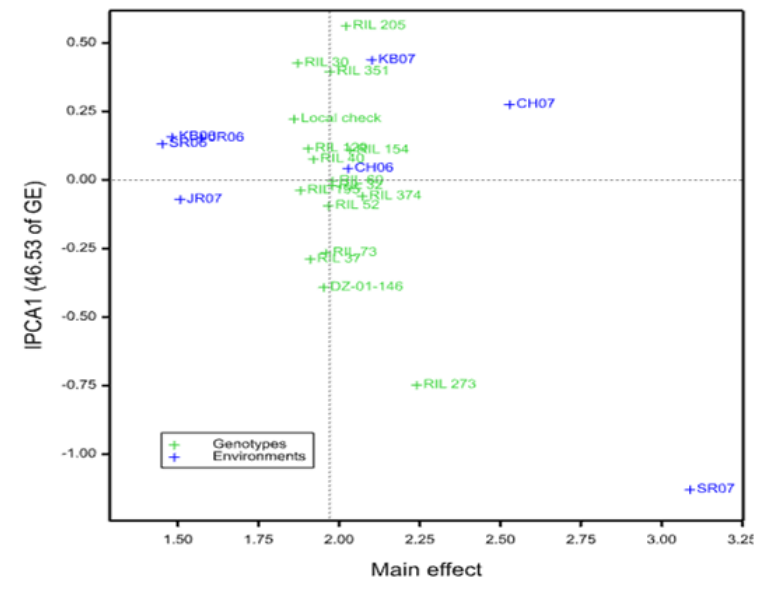

Figure 1. AMMI biplot of main effects of Tef genotypes and environments, and IPCA1. CH06 $=$ Chefa 2006, $\mathrm{CH07}=$ Chefa 2007, JR06= Jari 2006, JR07= Jari 2007, KB06= Kobo 2006, KB07 $=$ Kobo 2007, SR06= Sirinka 2006, SR07= Sirinka 2007
The result is in general agreement with the findings of Worede (2020). In the AMMI2 biplot, environment SR07 followed by $\mathrm{CH} 07$ and $\mathrm{KB} 06$ exerted comparatively higher interaction to the $\mathrm{G} \times \mathrm{E}$ variance; consequently, they are more discriminating. Environment JR07 followed by SR06, CH06 and JR06 exerted minimum interaction, hence less discriminating; while that of KB07 was moderate (Figure 2).

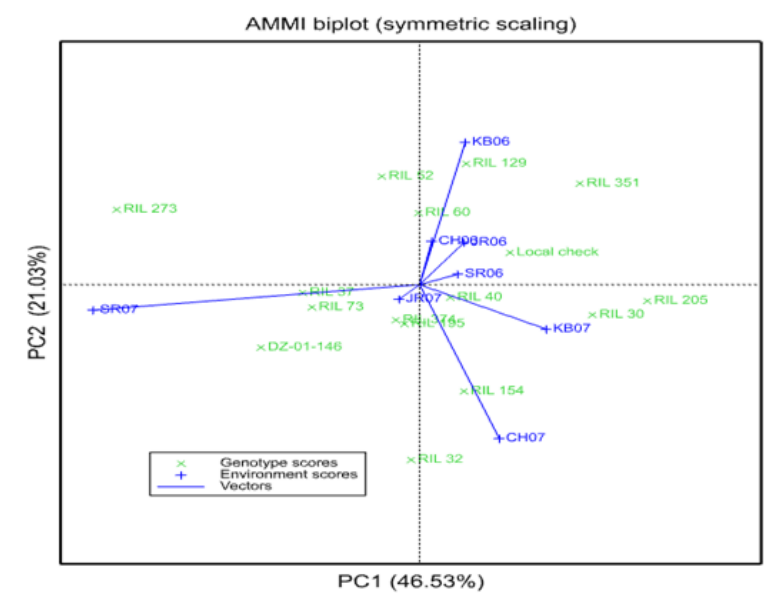

Figure 2. AMMI biplot of Tef genotypes and environments plotted against PCA1 and PCA2. CH06= Chefa 2006, CH07 $=$ Chefa 2007, JR06 $=$ Jari 2006, JR07 $=$ Jari 2007, KB06= Kobo 2006, KB07= Kobo 2007, SR06= Sirinka 2006, SR07= Sirinka 2007. 


\section{Black Sea Journal of Agriculture}

\subsection{Genotype plus Genotype-Environment Interaction Analysis}

The GGE biplot showed that $62.16 \%$ of the GGE variance was explained by the first $(44.29 \%)$ and the second (17.88\%) interaction PC axes (Figure 3 and 4). The central point of the concentric circles (pointed by an arrow) of GGE biplot (Figure 3) signifies an ideal genotype (Yan and Tinker, 2006). Genotype RIL273, which is proximal to the ideal genotype, is the most desirable (high-yielding and stable) genotype. Jifar et al. (2019) and Worede (2020) also recommended a variety of Tef by employing the same methodology. In contrast, RIL30 and RIL205 situated very far from the ideal genotype regarded as undesirable genotypes (Figure 3).

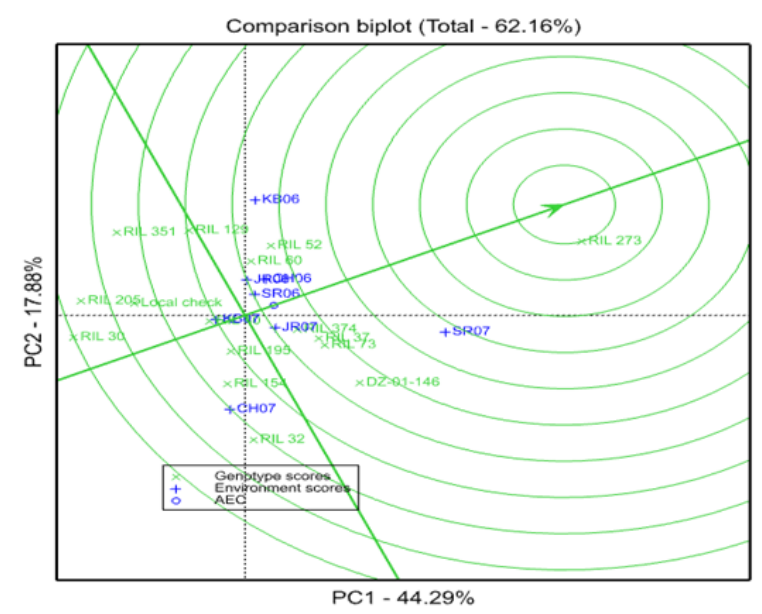

Figure 3. GGE biplot of 16 Tef genotypes on eight environments using genotype-centered scaling. CH06= Chefa 2006, CH07 $=$ Chefa 2007, JR06= Jari 2006, JR07= Jari 2007, KB06= Kobo 2006, KB07= Kobo 2007, SR06= Sirinka 2006, SR07= Sirinka 2007.

By the same fashion, the arrow at the center of the concentric circles of Figure 4 shows the ideal environment. Environment SR07, which is closer to the ideal environment, is the most desirable environment. The finding is in concurrence with Worede (2020) who identified an environment by employing same methodology. Nevertheless, $\mathrm{CHO}$ which is located very far from the ideal environment regarded as least desirable environment (Figure 4).

Based on the results of the multivariate stability (AMMI and GGE) analyses, RIL273 could be recommended as a suitable genotype for the locations (environments) considered. RIL273 is a recombinant inbred line developed from the cross of DZ-01-974 $\times$ DZ-01-196. One of the parents, DZ-01-974, is a high-yielding variety well adapted to the test locations (Worede et al., 2007). The genotype RIL273, together with the checks, was evaluated by farmers and they ranked it first based on its very white color, higher grain- and biomass-yield and early maturity. The genotype was released in 2010 and dubbed as Lakech.

Lakech is as early as the checks (matures within three months), is significantly taller, and had higher biomass- and grain-yield than the checks. It is adapted to low- and dry-land areas of Northeast Ethiopia, and possibly to similar agro-ecologies. It is one of the varieties developed by cross breeding or hybridization. This variety is a sister line to the famous Tef variety in Ethiopia known as Quncho (Assefa et al., 2011). Like Quncho (RIL355), Lakech has a very white seed and brown lemma color. Varieties with very white seed color are more preferred by consumers and have premium selling price at the local market. Being adapted to the semi-arid areas, having higher yield (both grain and biomass) and very white seed color, this variety will contribute to food security of the area.

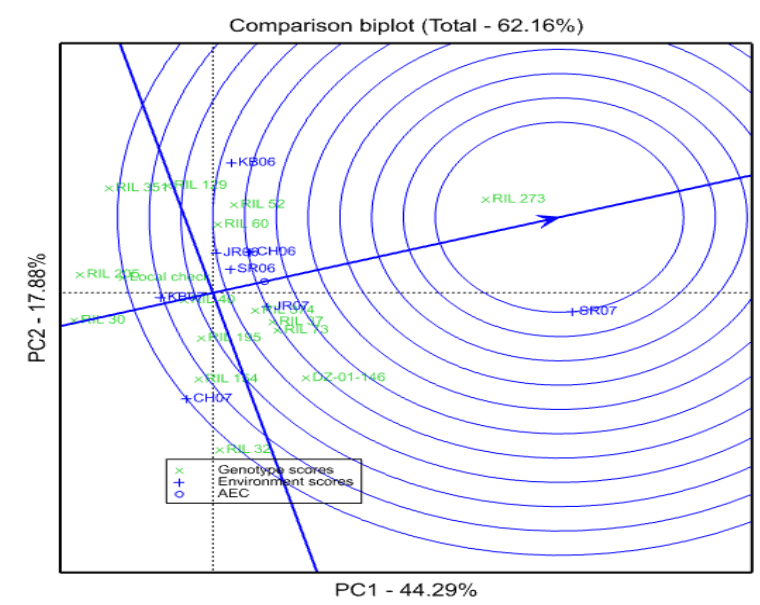

Figure 4. GGE biplot view to rank the eight Tef growing environments using environment-centered scaling. CH06 $=$ Chefa 2006, CH07 = Chefa 2007, JR06= Jari 2006, JR07 = Jari 2007, KB06= Kobo 2006, KB07= Kobo 2007, SR06 $=$ Sirinka 2006, SR07 $=$ Sirinka 2007.

\section{Author Contributions}

FW; initiated the research idea, suggested the research methods, analyzed and interpreted the result and wrote the manuscript. TM; implemented the research, collected and encoded the data.

\section{Conflict of Interest}

The author declare that there is no conflict of interest.

\section{Acknowledgements}

The research was financed by the Amhara Regional Agricultural Research Institute. The authors would like to extend appreciation to Tsegaye Gebremariam, Solomon Mitiku and Habtam Tesfaye for assisting in data collection.

\section{References}

Agegnehu G, Ghizaw A and Sinebo W. 2006. Crop productivity and land-use efficiency of a Teff/faba bean mixed cropping system in a tropical highland environment. Expl Agric, 42: 495-504.

Assefa K, Aliye S, Belay G, Metaferia G, Tefera H and Sorrells ME. 2011. Quncho: the first popular Tef variety in Ethiopia. Inter J Agri Sustain, 9(1): 25-34. 


\section{Black Sea Journal of Agriculture}

Balcha A. 2020. Additive Main Effects and Multiplicative Interaction and other stability analyses of Tef [Eragrostis Tef (Zucc.) Trotter] grain yield. American J Plant Sci, 11: 793-802. Bayu W, Addisu M, Tadesse B and Admassu L. 2007. Intercropping Tef and sunflower in semi-arid areas of Welo. Ethiopia. Trop. Sci. 47: 16-21.

Berehe T. 1976. Brighter prospects for improving Eragrostis tef by breeding. Evaluation of Seed Protein Alterations by Mutation Breeding. IAEA, 5 May, Vienna, Austria, 129-135.

CSA. 2019. Agricultural sample survey 2018/19. Area and production of major crops. Statistical bulletin 589. Addis Ababa. Ethiopia.

Ebba T. 1969. Tef (Eragrostis Tef). The cultivation, usage and some of its known diseases and insect pests. Part I. Expt Stat Bull, 60(1).

Gauch HG and Zobel RW. 1996. Additive Main Effect and Multiplicative Interaction analysis of yield trials. In: M.S. Kang and H.G. Gauch, editors. Genotype by environment interaction. CRC Press, Boca Raton, FL, 1th ed., pp. 85-122.

Jifar H, Assefa K, Tesfaye K, Dagne K and Tadele Z. 2019. Genotype-by-environment interaction and stability analysis in grain yield of improved Tef (Eragrostis Tef) varieties evaluated in Ethiopia. J Exper Agri Inter, 35(5): 1-13.

Ketema S. 1993. Tef (Eragrostis Tef): Breeding, genetic resources, agronomy, utilization and role in Ethiopian agriculture. Institute of Agricultural Research, Addis Ababa, Ethiopia, pp. 102.

Ketema S. 1997. Tef, Eragrostis Tef (Zucc.) Trotter. Promoting the Conservation and Use of Underutilized and Neglected Crops. 12. Institute of Plant Genetics and Crop Plant Research, Gatersleben/ IPGR, Rome, Italy, pp. 50.

Mengesha M-H, Pickett RC and Davis RL. 1965. Genetic variability and interrelationship of characters in Tef [Eragrostis Tef (Zucc.) Trotter]. Crop Sci. 5: 155-157.

Molla A. and Muhie K. 2011. Tef (Eragrostis Tef) based cropping systems in the hot to warm moist valleys of North Shewa, Ethiopia. Sci Res Essays 6: 1411-1416.

Spaenij-Dekking L, Kooy-Winkelaar Y and Koning F. 2005. The Ethiopian cereal Tef in celiac disease. N Engl J Med, 353: 1748-9.

Teklu Y and Tefera H. 2005. Genetic improvement in grain yield potential and associated agronomic traits of Tef (Eragrostis Tef). Euphytica 141: 247-254.

Vavilov N.I. 1951. The Origin, Variation Immunity and Breeding of Cultivated Plants. Translated from the Russian by K Srarrchester, Roland Press, New York, USA, 1th ed., pp. 37-38.

Worede F. 2020. Genotype-environment interaction and stability of Tef [Eragrostis Tef (Zucc.) Trotter] varieties in Northeast Ethiopia. BSJ Agri, 3(4): 239-245.

Worede F, Wondimu S and Shewayirga H. 2007. Performance of Tef varieties in moisture stress areas of Welo, Northeast Ethiopia. Proceedings of the 1st Annual Regional Conference on Completed Crop Research Activities, 14-17 August 2006. Amhara Regional Agricultural Research Institute. Bahir Dar, Ethiopia, pp. 178-182.

Worede F, Mehadi T and Wondimu S. 2020. Stability analyses of Tef (Eragrostis Tef [Zucc.] Trotter) grain yield in dryland areas of Northeast Ethiopia. Cogent Food Agri, 6(1): 1847760

Worku W. 2004. Maize-Tef relay intercropping as affected by maize planting pattern and leaf removal in southern Ethiopia. Afr Crop Sci J, 12: 359-367.

Yan W, Hunt LA, Sheng Q and Szlavnics Z. 2000. Cultivar evaluation and mega-environment investigation based on the GGE biplot. Crop Sci, 40: 597-605.

Yan W. and Tinker NA. 2006. Biplot analysis of multienvironment trial data: Principles and applications. Can. J. Plant Sci. 86: 623-645.

Zobel RW, Wright MJ and Gauch HG. 1988. Statistical analysis of a yield trial. Agron J, 80: 388-393. 